\title{
Implementation of Flipped Classroom Model and Its Effectiveness on English Speaking Performance
}

\author{
https://doi.org/10.3991/ijet.v14i09.10348 \\ Mohamad Yahya Abdullah( $\left.{ }^{\bowtie}\right)$ \\ Universiti Kebangsaan Malaysia, Selangor, Malaysia \\ Buraimi Univeristy College, AL Buraimi, Sultanate of Oman \\ mabdullah@buc.edu.om \\ Supyan Hussin, Kemboja Ismail \\ Universiti Kebangsaan Malaysia, Selangor, Malaysia
}

\begin{abstract}
In this study, combined method using pre and post oral proficiency tests, observation, and focus group interviews were used to examine the effectiveness of using flipped classroom model on English speaking performance. The study population consists of 27 undergraduate students who were attending the course of Advanced Communication Skills, in the academic year of 2018. A purposeful sampling technique, specifically quasi-experimental procedure was employed in this study. The analysis of quantitative and qualitative data showed that the application of FCM was an effective approach in the EFL speaking classroom. The results of paired-sample t-test indicated that there was a significant difference between pre and post oral proficiency tests $t(26)=$ $14.83, \mathrm{p}<0.001$. Moreover, it was found that students' involvement and willingness to participate in the English conversational tasks and their level of commitment and English speaking performance have increased gradually. In light of the findings, the study recommended encouraging teachers to employ modern technologies in their teaching strategies, particularly FCM.
\end{abstract}

Keywords-Flipped Classroom Model, English speaking performance, Classroom Environment, EFL context.

\section{Introduction}

In the domain of English language teaching and learning, speaking is considered one of the most important skills as to determining learners' aptitude to use the language efficiently. Numan [1] contends that the success of the second or foreign language learning process can be measured through learners' ability to perform a conversation. Thus, among the four language skills (speaking, listening, reading, and writing), speaking is considered as the most demanding skill as long as the ability to speak a language is judged the same as mastering that language. Brown [2] stated that speaking is an interactive process of constructing meaning that involves the actions of receiving, processing, and producing information due to the context of a speech. Simi- 
larly, Nunan [3] highlighted speaking skill as "the productive oral skill. It consists of producing systematic verbal utterance to convey meaning."

Without a doubt, the importance of English as a global language makes speaking English, as a demanding skill, needs to be developed and performed accurately and efficiently for better academic achievement and future career. Therefore, the mastery of English speaking performance has received much consideration and became a priority for most of teachers and learners. However, the weakness of English speaking performance remains one of the most widespread problems for the learners who are studying English as a Foreign Language (EFL). A clear dereliction of oral language development has occurred, which in turn caused the emergence of many speaking obstacles [4]. Fear of public speaking, lack of self-confidence and body language qualities, unwillingness to communicate, being laughed at, apprehension of speaking evaluation, and limited linguistic knowledge are identified as the most considerable challenges. [5] [6] [7]

\subsection{Study problem and research questions}

In the EFL context, learners still suffer from learning challenges that impact negatively on their English proficiency. It has been found that oral language development influences students negatively because of the teacher's dominant role in the language classroom whereby students lack opportunities to speak and practice the language. [8] [9] [4] Traditional teaching approaches focus on what the teachers (not students) are doing. The process of teaching represents the transmission of knowledge from the teacher to the passive learner. This type of instruction weakens teacher-student interaction as it is completely controlled by the teacher. [11], [12] Accordingly, the instructor dominates all aspects of the learning experience. Teacher's domination inside the classroom resulted students to be spoon-fed by their teacher. Furthermore, Anton, [13] argues that a teacher-centred approach provides limited opportunities for learners' negotiation within the sociocultural circumstances. Anton also states that the process of language learning with lack of scaffolding will not provide the required assistance for learners to help them keep progressing in the framework of the sociocultural theory. Moreover, Leman, [14] stated that the paucity of opportunities to use the language beyond the classroom leads EFL learners to lack interest and motivation in learning English language. Hence, students show negative attitudes towards English language because they perceive it as a course that is difficult to pass. These factors contribute directly to the existence of various problems in learning different skills; namely speaking skills. [4] Similarly, Rababa'h, [15] argued that many factors, such as teaching strategies, learners, curriculum, and the environment cause difficulties for EFL learners

Currently, educators in non-native English context are fully aware of the fact that language learning skills have been impacted by the changes that happen in the process of pedagogy. Therefore, many researchers who have been involved in this issue suggest that teachers should create an interactive and reciprocal atmosphere inside the classroom in order to facilitate the exploration of meaning and grant the students authentic opportunities to feel safe and accepted. [16] Moreover, the classroom at- 
mosphere has to afford students involvement and socialisation. Learners can communicate and take responsibility for the process of learning instead of being passive. Most importantly, learners should have the chance to express their ideas, use their past experiences, and concentrate on lifelong learning with the teacher, whose role is a facilitator. [17] [18] [19]

In the last decades, the advent of technology and the widespread of its applications has contributed significantly in bringing people closer. The ample implementation of computer technology in most aspects of life has led to the evolution in educational settings. This contribution creates richer learning environments whereby they offer a large number of opportunities to provide more adaptable learning programs. [20] [21]. Technology can be used extensively in the pedagogical practices to promote teachers with creating a connection between the traditional classroom and online activities. In the same sense, emerging technology in the pedagogical process paves the way to creating more flexible models of teaching and learning, such as Flipped Classroom Model (FCM). It embodies the concept of promoting learners the opportunity to construct their learning process, enhance their understanding, apply language skills, and communicate collaboratively with their peers. [22] [23] [24] Moreover, it provides learners with real chances to share information and negotiate meaning. [25] However, teacher's role within this process of communication is being the facilitator and the promoter. [26] [27] According to Arnold-Garza [22], flipped classroom is "a teaching method that delivers lecture content to students at home through electronic means and uses class time for practical application activities, may be useful for information literacy instruction". In other words, students study the basic concepts through the electronic means and comprehend them in depth at the classroom. This model enables students to spend the class time discussing the points further with their instructor and peers. It is a real opportunity to construct knowledge and negotiate meaning collaboratively throughout different activities designed by the teacher who is taking the role of a facilitator and a mentor of the classroom. In fact, the flipped classroom is conveying the real meaning of student-centered approach because it focuses on active learning. [28] [29]

Accordingly, the need to use FCM stems from a commonly held perspective on its characteristics, which seems to help generate positive attitudes towards the process of language learning. Here, teachers can involve their learners in the process of reciprocal interaction and meaning negotiation by providing them with adequate opportunities to speak and express themselves in order to overcome their speaking difficulties. Considering the well-established links between the features of FCM and foreign language achievement, which have been validated by the literature, this study examines if this model forms the best approach in which teachers can create interactive, encouraging, and engaging environment to help students overcome speaking difficulties and optimise their English speaking performance. The current study aims to answer the following questions:

- To what extent could the application of flipped classroom model have improved English speaking performance of EFL learners? 
- How do the participants react towards the application of flipped classroom model in their EFL speaking classroom?

\section{$2 \quad$ Literature Review}

Over the last two decades, the English language has witnessed a unique spread to all corners of the globe. This spread is playing a significant role in the evolution of most domains of life. Thus, English language learning has witnessed a rapid and incessant improvement, mainly the speaking skills. In the process of language learning, speaking has been well known as one of the most important facets of communication in which the ability of language learner is measured by the efficiency of their speaking performance. The fact that English is a global language has led to a demand for fluency and growth in efforts to find effective and practical methods to develop English speaking performance. [30] According to Luoma [31], the ability to communicate with friends, visitors, and colleagues in their language or in a language understood by both speakers and listeners, is the main target for most learners. Accordingly, the awareness on the serious need to improve the competency of English speaking performance has increased research interests significantly to ensure language teaching and learning techniques are updated. The study carried out by Kırkgöz [32], to explore the effectiveness of implementing blended learning in a speaking course, indicated positive impacts of students' viewing and critically evaluating their video recorded speaking tasks. Integrating technology into face-to-face instruction recorded a number of protentional advantages. Castañeda and Rodríguez-González [33] examined the effect of self-evaluation through video portfolio on speaking performance of Spanish undergraduate learners. The participants reported to show positive attitudes towards creating digital video for the reflections of their learning process. Also, the findings indicated the significant role of digital video in fostering learners' speaking performance.

On the other hand, the significant presence of integrating technology into the pedagogical process over the last two decades has influenced considerably the language learning process, particularly speaking skills. Undoubtedly, innovations in technologies facilitate human interactions in the synchronous and asynchronous online learning process. Flipped Classroom (FC) is one of the most significant technological innovations in the $21^{\text {st }}$ century. The pedagogical field has witnessed a widespread implementation of FC. Webb, et al. [34] conducted an experimental study to examine teachers and students perceptions on the Model of FC in Chinese universities. Students reported positive perceptions towards this model and felt more comfortable with flipped material. In addition, teachers acknowledged the role of FC model in promoting more creativity and better opportunity in the learning process. Earlier, Marlowe [35] investigated the effects of using FC on students' achievement and stress level. Participants showed significant improvement in their achievement by recording higher scores in their exams after the application of FC. The findings also reported students' lower stress level in the FC environment. Similarly, Talley and Scherer [36] stated that the FC technique facilitated meaningful study time that led to better exam 
grades. Hung [37] found that the FC technique has a notable role in fostering and developing speaking skills. Kostaras [38] stated that both teachers and students reported to show positive attitudes towards the use of FC regarding oral interaction. FC's pre-class preparation leads to an effective time-management for more interaction and conversational tasks in classroom, which were very limited before the emergence of this teaching technique. Moreover, Kurt [39] argued that FC teaching technique resulted in better learning outcomes and a higher level of self-efficacy as compared to the results of traditional classrooms.

To date, little evidence has been found on the implementation of FCM to optimise English speaking performance in the EFL context. Therefore, the current study is aimed to contribute to the body of literature on the implementation and effectiveness of employing FCM in EFL speaking classroom.

\subsection{Implementation of flipped classroom model}

In a typical flipped classroom environment, students are exposed to watch instructional videos outside of the classroom or prior to class. This enables students to learn at their own time and pace before the class session. Besides, it allows the instructors to use the class time for more practices, discussions, activities, and interactions. [40][41][34][42] These video lectures should be either recorded by the teachers or selected from an online source. Houston and Lin [43] recommended to "keep the videos relatively short (no longer than 20 to 30 minutes) to ensure that students watch them". However, the researcher of the current study recorded instructional video lectures ranging from 5-10 minutes based on what was suggested in a recent study conducted by Elian and Hamaidi [44]. In this process, all in-class lectures that were supposed to be giventraditionally were recorded by the teacher to prepare a repository of short videos for the course content. These instructional video lectures were recorded in very appropriate conditions with a high sufficiency of sound and image quality. Then, the teacher edited these clips by reviewing the content, testing the sound quality, dividing them into parts, and giving them titles.

The process of delivering the instructional video lectures to the students should be carried out via electronic devices for the students to learn at home or to use for inclass practice and interaction. For this process, there are a variety of electronic means (platforms) that can help to perform flipping, such as Moodle, Padlet, Edpuzzle, WizIQ, Google Classroom, and others. In the present study, Google Classroom was the best option because of several reasons. Firstly, it is the most common social platform in the context of the study. Most of the lecturers are using it to communicate with their students. Secondly, Google Classroom has a good number of features that may encourage teachers to employ it in the model of the flipped classroom. It is a functional repository to keep all the instructional video lectures and other materials. Teachers can re-use any of the instructional materials from class to class and at any time. It provides the students with the feature that enables them to download the lecture videos or any instructional material. It has a mobile application that makes the classroom accessible through different digital devices. This option allows students to watch the lecture videos anytime and anywhere. Besides, it helps teachers and stu- 
dents to communicate outside the classroom as needed. Finally, this platform is considered as a vital opportunity for peer learning. It allows students to post their comments, ask and answer questions, respond to their peers' replies, and share their knowledge and ideas.

\section{Methodology}

A combined method using a pre and post oral proficiency tests, observations, and focus group interviews were used to examine the effectiveness of using a flipped classroom model to optimise English speaking performance. By means of quantitative and qualitative methods, this design was used to support and obtain a complete picture of the study. However, qualitative data is presented with a greater weight than quantitative data.

\subsection{Research context and participants}

This study was carried out using the course of Advanced Communication Skills (ENGL 154) at the English department at Buraimi University College (BUC), as the research context. The participants of this research are 27 undergraduate students who were attending the course of (ENGL 154); the academic year 2018. According to the nature of the current study, a purposeful sampling technique, specifically the quasiexperimental procedure, was employed in this study. Creswell [45] stated that researches could use quasi-experimental design "when individuals are not randomly assigned." Purposeful sampling technique allows the researchers to exclude respondents who could not go along with the purpose of the study and select those who can best help the researcher to understand the problem and the research questions and provide sufficient information for the current study.

\subsection{Instruments}

Oral Proficiency Test: In this study, oral proficiency tests, using Individual Presentation Assessment Form (IPAF), were carried out before and after the application of FCM to assess participants' skills of English speaking performance. This oral proficiency assessment form is designed based on the guidelines of SOPA (Student Oral Proficiency Assessment) and ELLOPA (Early Language Listening and Oral Proficiency Assessment), and ACTFL (American Council on the Teaching of Foreign Languages) Proficiency (2012), particularly, ACTFL Performance Descriptors for Language Learners (Presentational). Nevertheless, it was modified to have a slightly different framework that meets the strands relevant to the course of advanced communication skills (ENGL 154). The assessment criteria of IPAF focus on the domains of appearing self-confidence and assurance, maintain acceptable body language, accuracy, fluency, and organisation. IPAF is divided into 4 bands; 1 to 4 , with 1 being poor and 4 the highest level of speaking performance. The scores based on the aforementioned five dimensions are added up to obtain the final score (20 marks) that 
determine the level of student's speaking performance level. This Assessment scale was revised and moderated by the committee of Oral Communication Skills and the Assessment Examination Committee at the English department in Al Buraimi University College. Besides, an inter-rater reliability test was performed to assess the consistency of speaking performance scores that are given by the three evaluators (the researcher and two internal evaluators).

Observation: The first qualitative instrument that was employed in the current study was observation, specifically participant observation. This flexible and powerful qualitative instrument helps the researcher sees things that might be unintentionally missed and explore things that participants might not speak out freely in the regular interview questioning (Cohen et al. 2007). Moreover, observational data (notes) was utilised as a secondary source of data relevant to the research questions and to triangulate data with other research instruments.

Focus group interview: In the current study, the third research instrument and the second most powerful qualitative method that was used to collect data was the focus group interview. According to Fraenkl \& Wallen (2003), the primary purpose of conducting interviews is to establish what is on the participants' minds - to find out what they think or how they feel deeply about the topic under investigation. The stratified purposive sampling technique was employed to select the interviewees of the current study. Twelve students were selected for the focus group interviews. They were selected and divided into three groups of 4 students according to their performance and commitment during the whole semester, in addition to their marks obtained in the post-oral proficiency test. The participants of the first group were from the highperforming students, the second group were from the middle-performing students, and the third group included participants from the low-performing students. This allowed the researcher to understand the phenomenon of the study from different perspectives. Stratification helps to capture variations and facilitate comparisons among responses. Patton [46] stated that "the purpose of a stratified purposeful sample is to capture major variations rather than to identify a common core, although the latter may also emerge in the analysis. Each of the strata would constitute a fairly homogeneous sample". The three interview sessions were conducted at the end of the semester, after the application of FCM.

\subsection{Data analysis}

The results of the overall IPAF pre and post-tests were compared statistically by using paired samples t-test. This test was run to show the differences in the mean scores between the pre and post-tests. In the present study, the paired sample t-test was conducted to test the null hypothesis, i.e., there is no significant difference between the overall mean scores of pre-test and post-test of participants' English speaking performance during the application of FCM. This test indicates whether the data are consistent with the hypothesis or inconsistent significantly. On the other hand, the data obtained from the qualitative research instruments were analysed using thematic analysis with the aid of NVivo 10 Qualitative Data Analysis Software. In the current study, findings are presented and reported based on the research questions. The re- 
search questions were answered through further interpreting the meaning of the findings, the researcher's reflections and views, as well as comparing and contrasting the findings with the literature.

\section{$4 \quad$ Results}

RQ1: To what extent could the application of flipped classroom model have improved English speaking performance of EFL learners?

This research question explores the differences between learners' English speaking performance before and after the application of FCM. To achieve this purpose, the overall mean score of learners' oral proficiency pre-test is compared to the overall mean score of their post-test. Table 1 shows the descriptive statistics for the total mean scores of the pre and post-tests.

Table 1. The descriptive analysis of pre-and post oral proficiency tests

\begin{tabular}{|l|c|c|c|}
\hline \multicolumn{1}{|c|}{ Oral Proficiency Tests } & Mean & N & Std. Deviation \\
\hline Pre-test & 12.2840 & 27 & 2.72014 \\
\hline Post-test & 15.5062 & 27 & 2.60894 \\
\hline
\end{tabular}

Table 1 displays the score level of English speaking performance before and after the application of FCM in the EFL speaking classroom. A paired t-test was used to compare the pre and post-tests results of the participants. The results show that the learners' post-test total score $(\mathrm{M}=12.28, \mathrm{SD}=2.608)$ is statistically higher than the total pre-test score $(\mathrm{M}=15.50, \mathrm{SD}=2.720)$, which reveals that participants' performance in the post-test was better than their performance in the pre-test, i.e. the learners' English speaking performance has increased significantly in the post-test results. Figure 1 visualises the differences of the total mean scores of pre and post-test results in oral proficiency tests.

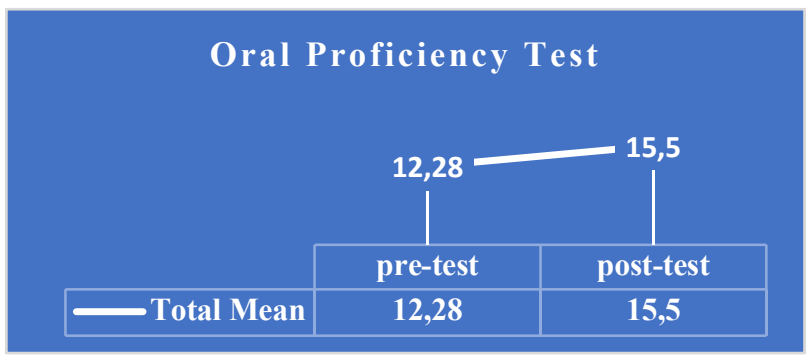

Fig. 1. Total mean scores of pre-test and post-test results of an oral proficiency test

Furthermore, a paired sample t-test (Table 2) was carried out to find out whether these observed differences between pre and post oral proficiency tests were statistically significant at the $\mathrm{p}<0.05$. 
Table 2. Paired sample t-test between pre and post oral proficiency tests

\begin{tabular}{|l|c|c|c|c|c|c|}
\hline Oral Proficiency Tests & Mean & Std. Deviation & Std. Error Mean & t & df & \\
\hline pre-test/post-test & -3.22222 & 1.12850 & 0.21718 & -14.837 & 26 & .000 \\
\hline
\end{tabular}

Table 2 illustrates that the results of paired sample t-test indicating that there is a significant difference between pre and post oral proficiency tests $t(26)=-14.83$, $\mathrm{p}<0.001$. Hence, the null hypothesis; (there is no difference between the mean scores of pre-test and post-test), is rejected. The descriptive and the paired sample t-test results reveal that the participants of the current study achieved better scores in their oral proficiency tests at the end of the FCM application as compared to their pre-test scores. These results indicated that the application of FCM in the EFL speaking classroom has significantly impacted the students' English speaking performance.

These results are strongly supported by the qualitative data obtained from the focus group interviews and notes obtained from the observation on the participants. At the interview sessions, the respondents rated their level of English speaking performance after the application of FCM as more developed and satisfied when compared to their performance before the application. They gave credit to the flipped classroom environment for the progress of their English speaking performance. FC has promoted them with authentic opportunities to practice and develop their speaking skills. In the following excerpts, the respondents reported their satisfaction and development of English speaking performance.

\subsection{FG1S4}

My English speaking is really good now and it's improved by flipped learning and because of many reasons, we talked a lot in the class, and we share our opinion from each other, and of course we have some students evaluate our speaking performance. So, this really helps us to be more good and we avoid the negative things or the bad things that we do and we try to make it better in the next time.

\section{2 $\quad$ FG3 S2}

Flipped learning is a great one.. cuz I have improved a lot in a way that I'm able now to speak in English even with my siblings. hmmm.... Even though, this would be impossible to happen in the past because I used to avoid doing that. I told them that, I've become very confident so no wonder that they keep their eyes wide open when I speak.

\subsection{FG1S1}

At the beginning I had some anxiety when I speak or when I be in front of my classmates at the end I feel confident to speak English and the rate of anxiety is being low. 


\subsection{FG2S4}

We become more confident because there are many chances to speak and participate. Flipped classroom helps us to decrease the anxiety. Yes! because 45 minutes for students to speak and practice so we become more confident with less anxiety and shyness.

Observation notes also revealed that the participants were very responsive and engaged in the classroom activities. Moreover, they became gradually more motivated and confident to take chances and opportunity to speak English. The majority of the students trusted the feedback from their teachers and peers on their speaking performance with high acceptance and appreciation.

Furthermore, the analysis of the qualitative data revealed that the majority of participants performed the different conversational activities comfortably due to the increase in their motivation and the decrease in their speaking anxiety. Finally, the flexibility of learning offered by the flipped classroom environment, the well-designed inclass and out-of-class activities, and the constant practice of speaking English were identified as important factors that encourage students to do various speaking activities confidently and without any stress.

Q. 2: How do the participants react towards the application of the flipped classroom model in their EFL speaking classroom?

Participants' perceptions and attitudes towards the use of FCM The analyses of the qualitative data obtained from participants' interviews and observation revealed that the majority of the students expressed positive perceptions and attitudes towards the application of FCM in their EFL speaking classroom. During the focus-group interview sessions, participants mentioned several reasons for their positive perceptions towards their English speaking performance within the FCM environment. Firstly, learners showed their satisfaction and ease with the learning process via FCM.

\subsection{FG3 S2}

I think this application is more than excellent because it gives us the chance to watch the recorded lecture at home more than once. This definitely helps us to understand it better and also, it makes it easy for us to have an idea about the next lecture so that we can be prepared for it. Watching recorded videos and lectures at home encourages the student to participate, share their points of view and interact with one another in the classroom.

Secondly, they felt good about the application of FCM due to the collaboration and interactions among participants, allowing them to share their opinions, enabling, and encouraging them to interact and discuss different topics with their peers.

\subsection{FG3 S1}

As I said before that using this app in our classroom enhances the sense of positivity among all the students. It also helps the students to be more cooperative and responsive. 


\subsection{FG3 S3}

Personally, I think this application is a good one, especially for those students who feel shy or unconfident when it comes to speaking or sharing their opinions with their peers. I strongly believe that this application is a wonderful tool that enables and encourages students to discuss anything related to the course.

Thirdly, FCM environment promotes them with authentic opportunities to practise speaking English language. This helps them to speak confidently and comfortably.

\subsection{FG3 S3}

For me it was super positive and the results are surely fruitful because everyone enjoyed being heard by others and that my ideas, discussion and so forth will be taken into consideration. Not only that, yet I learned to give others a chance to speak and discuss their points of view. This for sure was the reason behind many students in my classroom could share their opinions fearlessly.

\subsection{FG1 S4}

In my opinion I think flip learning really help me to be more confident and to be in a good body language and also as I was telling my friend that when I go and present, I really don't feel like nervous or afraid because I really do presentations and I really speech in the classroom so I...

Furthermore, they stated that the role they played as teachers is another reason for their positive perceptions towards the use of FCM. Students indicated that the role played, as well as the role of the teachers being facilitators and mentors, helped them to be more confident and active rather being passive learners. Besides, they felt more motivated and became more interested at learning and practising speaking English language.

\subsection{FG2 S4}

Teacher's role was really useful and limited to guide us observe, guide and give us comments. During the first lectures we felt worry and fear when we took teacher's role and give presentations while the teacher was standing at the back of the classroom and observing our performance. Then with time I feel more active, confident and comfortable to take the role of the teacher in the classroom.

\subsection{FG1 S4}

I think that the interaction between the students themselves and the students who were playing the role of teacher increased more, not like in other courses you know, I think students are lazy they don't interact as much as students interact in this course which use flipped learning so 1 think it is very effective way to increase the interaction 
between students themselves. Also, our teacher is having the role of mentor or guide I think that this is really good.

\subsection{FG2 S2}

I feel very happy for my role in this course and I am more confident and active. Now, I am more motivated to explain and to stand in front of my classmates and teacher. Not like other course, we only listen to the teacher then we sit for exams which is really boring.

Participants' challenges regarding the use of FCM: The participants were asked to clarify the challenges that they faced regarding the application of FCM. Almost all participants mentioned the same problems and difficulties that they face regarding FCM. The participants from the first group interviewed agreed that being very active learners in one course (where the FCM is applied), while being passive learners in the other courses (traditional method,) made them feel uncomfortable and less interested to be in the latter. They think that this might impact negatively on their performance and achievement in the courses that use traditional methods.

\subsection{FG1 S4}

Also, in this class, we all the time are speaking not sitting like other courses. Other courses we just sit and as my friend said we just take notes but in this course by using this method we are all the time speaking to our classmates or teacher. You know what, I start feel uninterested and uncomfortable to attend other courses and I fear this may have bad effects on my study and results.

Participants from the third group expressed another problem regarding the challenges related to culture shock by the digital world. They were reluctant to use technology in the classroom because they were so used to be in traditional classes, which they have experienced since primary school. The use of the FCM for the first time was intimidating for the students, representing a learning cultural shock, which they overcame rapidly during the first weeks of the application. In addition, some students felt hesitant to work in groups and shy to express their opinions and share their ideas.

\subsection{FG3 S3}

There are some cultural problems or hhmmmm 1 mean challenges. The use of FCM for the first time gave us the feelings of unwillingness to participate because we didn't have any previous experience about this before since primary school. But then, very quickly, I realized it is very very interesting.

\subsection{FG3 S4}

Also, when we knew we have to work in groups and share our ideas and opinions we felt very shy because I not get used to work in groups and share my opinions. 


\subsection{FG2 S1}

I also agree to the idea that this application is very useful. I really hope that the rest of my instructors will use it in their classroom too.

Based on the answers given by the participants, their views about the FCM have changed rapidly as they have become more interested and willing to adopt and adapt this application to other courses. Therefore, they encouraged other teachers to apply FCM in their classes. More importantly, the observation notes revealed that students' involvement and willingness to participate in the English conversational tasks and their level of commitment and English speaking performance have gradually increased.

\section{$5 \quad$ Discussion and Conclusion}

The growing implementations of technology and internet in the pedagogical process resulted a significant shift in teaching and learning methodologies, in general, and in language teaching and learning, in particular. [47] This led to a growing trend towards the integration of the recent technologies to create a helpful, encouraging, and engaging learning environment to enhance learners' abilities and overcome various problems in the learning and teaching of speaking skills. This study is aimed to investigate the effectiveness of implementing FCM on the English speaking performance of EFL learners. In this quasi experimental study, both quantitative and qualitative data were obtained to achieve the research questions of the current study. The results of the current study are generally similar with those from previous studies with regard to the contribution of flipped classroom to the improvement of students' outcomes. However, the previous research has focused largely on students' perceptions rather than investigating students' speaking performance. Lin and Hwang [48] found that FCM helped students to be more responsible and independent in their learning process, in general, and communication in particular. In addition, the students showed better collaborating behaviors and greater satisfaction. Similarly, Fisher et al. [49] found that the application of flipped classroom had a significant contribution to learners' perceptions of learning satisfaction, engagement. and less regarding their performance. Due to the novelty of this teaching approach, there is a limited number of educational research outcomes regarding the impacts of flipped classroom on learners' performance. [49]

Taken as a whole, the findings of this study seem to indicate that the application of FCM is an effective approach in the EFL speaking classroom. First, the key finding is for the English speaking performance aspect. FCM plays a highly positive role in enhancing students' speaking performance over the in-class and out-of-class activities. The quantitative data indicated that students recorded better scores in the post oral proficiency test as compared to their scores in the pre-test. The paired sample ttest showed that there was a significant difference in the total mean scores of students speaking performance at the end of the study $(* * p>001)$. This result was consistent with the qualitative data obtained from the classroom observation and interview sessions. The data acquired from respondents revealed that learners are aware on the 
gradual progress in their speaking performance over time. This significant result is also supported by the observation notes whereby a noticeable development in learners' speaking performance was recorded. Second, the analysis of the qualitative data revealed that the majority of participants performed the different conversational activities comfortably due to the increase in their motivation and the decrease in their speaking anxiety. Moreover, the flexibility of learning offered by the flipped classroom environment, the well-designed in-class and out-of-class activities, and the constant practice of English speaking were all important factors that encourage students to do the various speaking activities with confident and without any stress. Moreover, the observation notes also revealed that the participants were very responsive and engaged in the classroom activities. This supported the previous study by Zainuddin and Attaran [50] who stated that flipped learning contributed effectively to encourage shy and quiet students to overcome their learning challenges through promoting more time for learning. Chen Hsieh, et al. [51] indicated that flipped learning is successful in making students more active in their oral interaction, significantly improving their knowledge, enhancing their motivation, and achieving the instructional goals of the class. Besides, Afrilyasanti, et al. [52] stated that the students found the activities applied in the flipped classroom model helped them to achieve better learning outcomes.

Third, the findings revealed that participants show high level of acceptance and appreciation to the feedback by their teachers and peers on their speaking performance, hence becoming more motivated and confident to take any opportunity to speak English. This indicated the vital role of feedback to motivate students and increase their self-confidence. [53] Fourth, regarding their reactions, participants expressed positive perceptions and attitudes towards the application of FCM. They showed a high level of satisfaction and comfortable with the FCM environment due to the collaboration and interaction among participants. They agreed that this classroom environment has promoted them with more opportunities to practise the target language besides making them feel confident and comfortable to speak English.

In terms of problems and difficulties, participants claimed that the application of FCM in their EFL speaking class made them feel dissatisfied about other courses that still continue using traditional teaching methods, which in turn influenced negatively their performance and achievement. Accordingly, they highly recommended other teachers to adopt the FCM and apply consistently in their courses. Moreover, cultural challenges in terms of being shocked by the digital world and being shy to express their opinions were observed as learning problems and difficulties during the application of FCM.

In conclusion, what is unique about the current study is that it merges teachers' views (as a participant observer) and students' opinions on different themes, such as teaching methods, learning styles, and learners' attitudes in regard to the phenomenon under investigation. The in-depth exploration to these findings shows that the application of the FCM enables the teacher to create an interactive, encouraging, and helpful classroom environment. The well-designed in-class and out-of-class activities, which are built based on the concept of cooperative and flexible learning, supported by the FCM characteristics, provide learners a constant speaking practice. This environment 
enables students to do various activities with confident and at ease. Moreover, students' involvement and willingness to participate in the English conversational tasks, as well as their level of commitment and gradual increase in their English speaking performance, have shown significant benefits and the effectiveness of the FCM.

Furthermore, what sets this study apart from other studies is that this study is the first to examine the effectiveness of implementing FCM on English speaking performance, particularly in the EFL context. Accordingly, the findings of this study may have significant implications on curriculum reform, particularly teaching speaking skills. The movement towards a more interactive learning environment should take the implementation of FCM into consideration to facilitate the process of learning.

\section{References}

[1] D. Numan, "Language teaching methodology: A textbook for teachers," New York, 1991.

[2] H. D. Brown and H. Lee, Teaching by principles: An interactive approach to language pedagogy, vol. 1. Prentice Hall Regents Englewood Cliffs, NJ, 1994.

[3] D. Nunan, Practical English language teaching. McGraw-Hill/Contemporary, 2003.

[4] S. Al Hosni, "Speaking difficulties encountered by young EFL learners," Int. J. Stud. English Lang. Lit., vol. 2, no. 6, pp. 22-30, 2014.

[5] S. Aydin, "An Investigation on the Language Anxiety and Fear of Negative Evaluation among Turkish EFL Learners.," Online Submiss., 2008.

[6] Ö. Yalçın and V. İnceçay, "Foreign Language Speaking Anxiety: The case of Spontaneous Speaking Activities," Procedia - Soc. Behav. Sci., vol. 116, pp. 2620-2624, 2014. https://doi.org/10.1016/j.sbspro.2014.01.623

[7] B. F. Klimova, "Detecting the development of language skills in current English language teaching in the Czech Republic," Procedia-Social Behav. Sci., vol. 158, pp. 85-92, 2014. https://doi.org/10.1016/j.sbspro.2014.12.037

[8] W. Littlewood, Foreign and second language learning: Language acquisition research and its implications for the classroom. Cambridge University Press, 1984. https://doi.org/10.3138/cmlr.44.1.179

[9] S. B. Al Busaidi, “An Investigation of Teachers' and Students' Attitudes Towards the Use of Mother Tongue in English Foreign Language Classrooms in Oman," Center for Applied Language Studies, University of Reading, 1998.

[10] S. Al Hosni, "Speaking Difficulties Encountered by Young EFL Learners," vol. 2, no. 6, pp. 22-30, 2004.

[11] R. Donato, "Collective scaffolding in second language learning," Vygotskian approaches to Second Lang. Res., vol. 33456, 1994.

[12] L. I. Danli, "Scaffolding in the second language learning of target forms in peer interaction," Chinese J. Appl. Linguist., vol. 34, no. 4, pp. 107-126, 2011. https://doi.org/10.1515/cjal.2011.037

[13] M. Anton, "The discourse of a Learner-Centered classroom: Sociocultural perspectives on Teacher-Learner interaction in the Second-Language classroom,” Mod. Lang. J., vol. 83, no. 3, pp. 303-318, 1999. https://doi.org/10.1111/0026-7902.00024

[14] F. Bin Leman, "Problems in learning English in rural secondary schools: A case study," Unpubl. MA thesis, Fac. Educ. Univ. Kebangs. Malaysia, 2003.

[15] G. Rababah, “Communication Problems Facing Arab Learners of English.” 2002. 
[16] M. Y. Abdullah, H. M. H. Al Ghafri, and K. S. H. Al Yahyai, "A Qualitative Study on the Best Motivational Teaching Strategies in the Context of Oman: Perspectives of EFL Teachers," English Lang. Teach., vol. 12, no. 3, p. 57, 2019. https://doi.org/10. 5539/elt.v12n3p57

[17] M. W. Keyser, "Active learning and cooperative learning: understanding the difference and using both styles effectively," Res. Strateg., vol. 17, no. 1, pp. 35-44, 2000. https://doi.org/10.1016/s0734-3310(00)00022-7

[18] R. L. Wright, "Walking the walk," CBE-Life Sci. Educ., vol. 5, no. 4, pp. 311-312,

[19] M. Weimer, Learner-centered teaching: Five key changes to practice. John Wiley \& Sons, 2002.

[20] A. I. Challob, N. A. Bakar, and H. Latif, "Collaborative Blended Learning Writing Environment: Effects on EFL Students' Writing Apprehension and Writing Performance," English Lang. Teach., vol. 9, no. 6, p. 229, 2016. https://doi.org/10.5539/elt.v9n6p229

[21] M. Y. Abdullah, "An investigation on the effects of CMC applications on ESL/EFL writing anxiety among postgraduate students at UKM," Unpubl. MA thesis, Univ. Kebangs. Malaysia, Bangi, Malaysia, 2011.

[22] S. Arnold-Garza, "The flipped classroom teaching model and its use for information literacy instruction," Commun. Inf. Lit., vol. 8, no. 1, p. 9, 2014.

[23] R. Khalil, M. Rania, and S. S. Fahim, "Assessment as a Learning Tool in a Flipped English Language Classroom in Higher Education," 2017.

[24] S. D. Ülugüten, "ve Balc\{\i\}, Ö. 2017." Flipped Learning.",’ J. Süleyman Demirel Univ. Inst. Soc. Sci., vol. 26, no. 1, pp. 253-265.

[25] S. Hussin, M. Y. Abdullah, N. Ismail, and S. K. Yoke, "The Effects of CMC Applications on ESL Writing Anxiety among Postgraduate Students," English Lang. Teach., vol. 8, no. 9, p. 167, 2015. https://doi.org/10.5539/elt.v8n9p167

[26] E. Rossiou, "Digital Natives... are Changed: An Educational Scenario With LAMS Integration That Promotes Collaboration via Blended Learning in Secondary Education," Proc. 11th Eur. Confernece e-Learning ECEL, p. 468, 2012.

[27] P. H. I. Chin, "The effect of Asian students' culture on perceptions of blended learning instructional design," University of the Incarnate Word, 2015.

[28] S. Freeman et al., "Prescribed active learning increases performance in introductory biology," CBE-Life Sci. Educ., vol. 6, no. 2, pp. 132-139, 2007.

[29] S. Chaplin, "Assessment of the impact of case studies on student learning gains in an introductory biology course," J. Coll. Sci. Teach., vol. 39, no. 1, p. 72, 2009.

[30] J. Harb, N. A. Bakar, and P. Krish, "Gender differences in attitudes towards learning oral skills using technology," Educ. Inf. Technol., vol. 19, no. 4, pp. 805-816, 2014. https://doi.org/10.1007/s10639-013-9253-0

[31] S. Luoma, Assessing speaking. Ernst Klett Sprachen, 2004.

[32] Y. Kirkgoz, "A Blended Learning Study on Implementing Video Recorded Speaking Tasks in Task-Based Classroom Instruction.," Turkish Online J. Educ. Technol., vol. 10, no. 4, pp. 1-13, 2011.

[33] M. Castañeda and E. Rodríguez-gonzález, "L2 Speaking Self-ability Perceptions Language educators and administrators that speaking is a vital yet complex skill in," Am. Assoc. Teach. Spanish Port., vol. 94, no. 3, pp. 483-501, 2017.

[34] M. Webb, E. Doman, and K. Pusey, "Flipping a Chinese university EFL course: What students and teachers think of the model," J. Asiat., vol. 11, no. 4, pp. 53-87, 2014.

[35] C. A. Marlowe and others, "The effect of the flipped classroom on student achievement and stress," 2012. 
[36] C. P. Talley and S. Scherer, "The enhanced flipped classroom: Increasing academic performance with student-recorded lectures and practice testing in a" flipped" STEM course," J. Negro Educ., vol. 82, no. 3, pp. 339-347, 2013. https://doi.org/10.77 $\underline{09 / \text { jnegroeducation.82.3.0339 }}$

[37] H.-T. Hung, "Flipping the classroom for English language learners to foster active learning," Comput. Assist. Lang. Learn., vol. 28, no. 1, pp. 81-96, 2015. https://doi.org/10.1 $\underline{080 / 09588221.2014 .967701}$

[38] V. Kostaras, "Flipped Classroom: A Literature Review on the Benefits and Drawbacks of theReversed Classroom." 2017.

[39] G. Kurt, "Implementing the flipped classroom in teacher education: Evidence from Turkey,” Educ. Technol. Soc., vol. 20, no. 1, pp. 211-221, 2017.

[40] J. Bergmann and A. Sams, Flip your classroom: Reach every student in every class every day. International society for technology in education, 2012. https://doi.org/10.11 77/073989131401100120

[41] J. L. Bishop, M. A. Verleger, and others, "The flipped classroom: A survey of the research," in ASEE national conference proceedings, Atlanta, GA, 2013, vol. 30, no. 9, pp. $1-18$.

[42] B. Danker, "Using flipped classroom approach to explore deep learning in large classrooms.," IAFOR J. Educ., vol. 3, no. 1, pp. 171-186, 2015. https://doi.org/10.22492/ije.3.1.10

[43] M. Houston and L. Lin, "Humanizing the Classroom by Flipping the Homework versus Lecture Equation,” Soc. Inf. Technol. Teach. Educ. Int. Conf. SITE 2012, pp. 1177-1182, 2012.

[44] S. A. Elian and D. A. Hamaidi, "The effect of using flipped classroom strategy on the academic achievement of fourth grade students in Jordan,” Int. J. Emerg. Technol. Learn., vol. 13, no. 2, pp. 110-125, 2018. https://doi.org/10.3991/ijet.v13i02.7816

[45] J. W. Creswell and J. D. Creswell, Research design: Qualitative, quantitative, and mixed methods approaches. Sage publications, 2017.

[46] M. Q. Patton, Qualitative evaluation and research methods. SAGE Publications, inc,

[47] A. I. Challob, N. A. Bakar, and H. Latif, "Collaborative Blended Learning Writing Environment: Effects on EFL Students' Writing Apprehension and Writing Performance," English Lang. Teach., vol. 9, no. 6, p. 229, 2016. https://doi.org/10.5539/elt.v9n6p229

[48] C. J. Lin and G. J. Hwang, "A learning analytics approach to investigating factors affecting EFL students' oral performance in a flipped classroom," Educ. Technol. Soc., vol. 21, no. 2, pp. 205-219, 2018.

[49] R. Fisher, Á. Perényi, and N. Birdthistle, "The positive relationship between flipped and blended learning and student engagement, performance and satisfaction," Act. Learn. High. Educ., p. 146978741880170, 2018. https://doi.org/10.1177/1469787418801702

[50] Z. Zainuddin and S. H. Halili, "International Review of Research in Open and Distributed Learning Flipped Classroom Research and Trends from Different Fields of Study," Int. Rev. Res. Open Distrib. Learn. vol. 17, no. 3, pp. 1-18, 2016. https://doi.org/10.1 9173/irrodl.v17i3.2274

[51] J. S. Chen Hsieh, W.-C. V. Wu, and M. W. Marek, "Using the flipped classroom to enhance EFL learning," Comput. Assist. Lang. Learn., vol. 30, no. 1-2, pp. 1-21, 2017. https://doi.org/10.1080/09588221.2015.1111910

[52] R. Afrilyasanti, B. Y. Cahyono, and U. P. Astuti, “Indonesian EFL Students' Perceptions on the Implementation of Flipped Classroom Model," J. Lang. Teach. Res., vol. 8, no. 3, pp. 476-484, 2017. https://doi.org/10.17507/jltr.0803.05 
Paper-Implementation of Flipped Classroom Model and Its Effectiveness on English Speaking ..

[53] M. Y. Abdullah, S. Hussin, and M. Shakir, "The Effect of Peers' and Teacher's EFeedback on Writing Anxiety Level Through CMC Applications," Int. J. Emerg. Technol. Learn., vol. 13, no. 11, pp. 196-207, 2018. https://doi.org/10.3991/ijet.v13i11.8448

\section{Authors}

Mohamad Yahya Abdullah is an Iraqi PhD candidate, English Language Studies. $\mathrm{He}$ is currently deputy of head of English Department at Buarimi University College. $\mathrm{He}$ is specializing in Applied Linguistics. His research interests include Teaching English as Foreign Language, E-learning, Information and Communication Technology.

Supyan Hussin is a Malaysian Professor at the Center for Literacy and Sociocultural Transformation (CLaST), Faculty of Social Sciences and Humanities, Universiti Kebangsaan Malaysia. He is currently the Director of the Institute of the Malay World \& Civilization (ATMA), UKM. He is specializing in language education and technology. He has published 7 books and more than 200 articles in chapters in books, journals, and proceedings at national and international levels. supyan@ukm.edu.my

Kemboja Ismail (Ph.D) is a Malaysian senior lecturer at the Faculty of Social Sciences and Humanities, Universiti Kebangsaan Malaysia. She was the Head of English Language Studies Programme at the Center for Literacy and Sociocultural Transformation from 2014 - April 2018. Her research interests include Academic Reading and Writing, Assessment, e-Learning and multimodality in teaching and learning. oja@ukm.edu.my

Article submitted 2019-02-20. Resubmitted 2019-04-04. Final acceptance 2019-04-14. Final version published as submitted by the authors 